\title{
Nutritional status and CD4 cell counts in patients with HIV/AIDS receiving antiretroviral therapy
}

\author{
Ana Célia Oliveira dos Santos ${ }^{[1]}$ and Ana Maria Rampeloti Almeida ${ }^{[2]}$
}

[1]. Instituto de Ciências Biológicas, Universidade de Pernambuco, Recife, PE. [2]. Programa de Mestrado em Ciências da Saúde, Faculdade de Ciências Médicas, Universidade de Pernambuco, Recife, PE.

\begin{abstract}
Introduction: Even with current highly active antiretroviral therapy, individuals with AIDS continue to exhibit important nutritional deficits and reduced levels of albumin and hemoglobin, which may be directly related to their cluster of differentiation 4 (CD4) cell counts. The aim of this study was to characterize the nutritional status of individuals with human immunodeficiency virus/acquired immunodeficiency syndrome (HIV/AIDS) and relate the findings to the albumin level, hemoglobin level and CD4 cell count. Methods: Patients over 20 years of age with AIDS who were hospitalized in a university hospital and were receiving antiretroviral therapy were studied with regard to clinical, anthropometric, biochemical and sociodemographic characteristics. Body mass index, percentage of weight loss, arm circumference, triceps skinfold and arm muscle circumference were analyzed. Data on albumin, hemoglobin, hematocrit and CD4 cell count were obtained from patient charts. Statistical analysis was performed using Fisher's exact test, Student's t-test for independent variables and the Mann-Whitney U-test. The level of significance was set to $0.05(\alpha=5 \%)$. Statistical analysis was performed using Statistical Package for the Social Sciences (SPSS) 17.0 software for Windows. Results: Of the 50 patients evaluated, $70 \%$ were male. The prevalence of malnutrition was higher when the definition was based on arm circumference and triceps skinfold measurement. The concentrations of all biochemical variables were significantly lower among patients with a body mass index of less than $18.5 \mathrm{~kg} / \mathrm{m}^{2}$. The CD4 cell count, albumin, hemoglobin and hematocrit anthropometric measures were directly related to each other. Conclusions: These findings underscore the importance of nutritional follow-up for underweight patients with AIDS, as nutritional status proved to be related to important biochemical alterations.
\end{abstract}

Keywords: HIV/AIDS. Nutritional status. Anemia

\section{INTRODUCTION}

With the introduction of highly active antiretroviral therapy (HAART), the population infected with human immunodeficiency virus (HIV) has experienced a substantial increase in life expectancy and quality of life. However, malnutrition remains a concern in patients with acquired immune deficiency syndrome (AIDS) ${ }^{1}$. Individuals with HIV undergo various physiological alterations beginning in the early phase of the infection. Malnutrition was one of the first complications of AIDS to be recognized and one of the most frequent diagnoses in the population infected with HIV. Several studies have demonstrated an association between lean mass depletion/ malnutrition and disease progression/patient survival ${ }^{2,3}$. The impaired nutritional status of patients with HIV is partially caused by the reduction in calorie intake, the occurrence of

\footnotetext{
Address to: Dra Ana Célia Oliveira dos Santos. R. Dona Inês Correia de Araújo 116, Caxangá, 50800-220 Recife, PE, Brasil.

Phone: 5581 9978-8103

e-mail: ana.oliveira@upe.br; ana.celia@pq.cnpq.br

Received 12 June 2013

Accepted 21 November 2013
}

opportunistic diseases and the hypercatabolic action of the body in an attempt to control viral replication and recompose the immune system ${ }^{4}$. In a cross-sectional study using secondary information from the Brazilian Mortality Information System (Sistema de Informações sobre Mortalidade - SIM), 7.4\% of cases of death were associated with endocrine, nutritional and metabolic diseases ${ }^{5}$.

In patients with HIV, there is an association among low albumin levels $\mathrm{s}^{6,7}$, low body mass index (BMI) and CD4 count $<200$ cells $/ \mathrm{mm}^{3}$. These variables are indications of nutritional deficiency, which is also demonstrated by the high prevalence of anemia, the etiological factors of which include the side effects of medications, opportunistic diseases and HIV itself ${ }^{8,9}$. The risk of developing AIDS-associated anemia is increased in patients with a CD 4 cell count $<200$ cells $/ \mathrm{mm}^{3}$, those taking zidovudine, those with a history of fever, those with oral candidiasis or bacterial pneumonia, those of African descent, those of female sex, those with lower muscle mass, those of advanced age or those with a high viral load ${ }^{10,11}$.

Years after the introduction of HAART in Brazil, groups of patients with HIV still exhibit clinical and nutritional characteristics common to the pre-HAART era. Thus, the aim of the present study was to identify the nutritional profile of this population and determine how this profile relates to important biochemical variables. 


\section{METHODS}

Patients hospitalized in the Infectious Disease Clinics of the Oswaldo Cruz University Hospital in the City of Recife in Pernambuco (Brazil) between March and October 2011 were evaluated. This institution is a reference hospital for infectious diseases in the State of Pernambuco (northeastern Brazil) and primarily treats a population with a low socioeconomic status in addition to homeless individuals and drug users. The following were the inclusion criteria: age between 20 and 60 years or older, diagnosis of HIV, treatment with HAART and agreement to participate in the study through a signed statement of informed consent. Patients who required intensive care during hospitalization were excluded, and patients using ferrous sulfate, those with bleeding or those who had undergone surgery in the last six months were also excluded.

Data on albumin, hemoglobin, hematocrit and CD4 cell count were obtained from patient charts. The following were the reference values for findings considered normal: albumin higher than $3.5 \mathrm{~g} / \mathrm{dl}$ in both sexes; hemoglobin equal to or higher than $14 \mathrm{~g} / \mathrm{dl}$ and hematocrit equal to or higher than $44 \%$ for men; and hemoglobin equal to or higher than $12 \mathrm{~g} / \mathrm{dl}$ and hematocrit equal to or higher than $38 \%$ for women. For stratification of anemia, a hemoglobin concentration lower than $8 \mathrm{~g} / \mathrm{dl}$ was considered severely reduced, a hemoglobin concentration between 8 and $12 \mathrm{~g} / \mathrm{dl}$ was considered moderately reduced and a hemoglobin concentration equal to or higher than $12 \mathrm{~g} / \mathrm{dl}$ was considered mildly reduced or normal. The CD4 cell count was interpreted based on the recommendations of the Brazilian Ministry of Health, which uses $200 \mathrm{cells} / \mathrm{mm}^{3}$ as the cutoff point (lower than $200 \mathrm{cells} / \mathrm{mm}^{3}$ is one of the criteria used to define AIDS in patients with HIV, together with nutritional status and the presence of opportunistic diseases) ${ }^{12}$.

The nutritional evaluation was performed once within $72 \mathrm{~h}$ of admission and included an anthropometric evaluation and history of weight loss. Weight was determined using a digital scale with a maximal capacity of $140 \mathrm{~kg}$ and a precision of $100 \mathrm{~g}$. Height was determined using a metal stadiometer coupled to the digital scale with a capacity of $2 \mathrm{~m}$ and a precision of $1 \mathrm{~cm}$. Arm circumference (AC) and triceps skinfold (TSF) were measured following the methods described by Lohman et $\mathrm{al}^{13}$. For bed-ridden patients, weight and height were estimated using formulas proposed by Chumlea et a ${ }^{14}$. Calf circumference, AC, TSF and subscapular skinfold were measured following the methods described by Lee and Nieman ${ }^{15}$, and the height of the knee was measured following the method described by Chumlea et $\mathrm{al}^{14}$. Arm muscle circumference (AMC) was estimated using the formula proposed by Frisancho ${ }^{16}$.

Based on the BMI, the patients were classified as either underweight (BMI $<18.5 \mathrm{~kg} / \mathrm{m}^{2}$ ) or adequate weight (BMI $\geq$ $18.5 \mathrm{~kg} / \mathrm{m}^{2}$ ). The percent weight loss was stratified as $<10 \%$ or $\geq 10 \%$ in relation to habitual weight. AC, TSF and AMC measurements were compared to the references values proposed by Blackburn and Thornton ${ }^{17}$, and classified as $<90 \%$ or $\geq 90 \%$ adequate.
The variables were represented by pertinent descriptive statistics: absolute (n) and relative (\%) frequency or mean and standard deviation (SD). Fisher's exact test was used to determine associations among the categorical variables. Student's t-test for independent variables was used to compare means among groups of interest. The Mann Whitney U-test was used to analyze the difference between the medians of two data sets. The level of significance was set to $0.05(\alpha=5 \%)$. The statistical analysis was performed using SPSS 17.0 software for Windows.

\section{Ethical considerations}

This study received approval from the local Human Research Ethics Committee under process number 014/2011.

\section{RESULTS}

Fifty patients were evaluated (mean age: $36.54 \pm 12.1$ years). Table 1 displays the characteristics of the sample.

The mean BMI was $19.64 \mathrm{~kg} / \mathrm{m}^{2}$ (SD $4.6 \mathrm{~kg} / \mathrm{m}^{2}$ ). The prevalence of malnutrition differed based on the measure employed. AC and TSF adequacy were associated with a higher number of diagnoses of malnutrition. Among the patients

TABLE 1 - Demographic, nutritional and clinical characteristics of patients with HIV receiving HAART and hospitalized at the Oswaldo Cruz University Hospital in Recife, Brazil, in 2011.

\begin{tabular}{lcc}
\hline Characteristic & Number & Percentage \\
\hline Demographic & 35 & 70.0 \\
male sex & 33 & 66.0 \\
age: $19-39$ years & 14 & 28.0 \\
age: $40-59$ year & 6 & 6.0 \\
age $\geq 60$ years & & \\
\hline Nutritional & 26 & 52.0 \\
BMI $<18.5 \mathrm{~kg} / \mathrm{m}^{2}$ & 35 & 70.0 \\
weight loss $\geq 10 \%$ & 30 & 60.0 \\
AMC $<90 \%$ adequate & 41 & 82.0 \\
TSF $<90 \%$ adequate & 41 & 82.0 \\
AC $<90 \%$ adequate & & \\
\hline Clinical & 28 & 56.0 \\
time since diagnosis $\geq 2$ years & 36 & 70.0 \\
CD4 cell count $<200$ cells $/ \mathrm{mm}^{3}$ & 36 & 70.0 \\
concentration of albumin $<3.5 \mathrm{~g} / \mathrm{dl}$ & 40 & 80.0 \\
hemoglobin $<12 \mathrm{~g} / \mathrm{dl}$ & 41 & 82.0 \\
hematocrit $<38 \%$ & & \\
\hline
\end{tabular}

HIV: human immunodeficiency virus; HAART: highly active antiretroviral therapy; BMI: body mass index; AMC: arm muscle circumference; TSF: triceps skinfold; AC: arm circumference; CD4: cluster of differentiation 4. 
considered malnourished based on the BMI, all (100\%) had a weight loss higher than $10 \%$ of the habitual weight.

When classified based on the BMI, both groups of patients had different means with regard to the number of leukocytes and lymphocytes, the hematocrit and the levels of hemoglobin and serum albumin, with statistically significant differences in the last three measures (Table 2).

The mean albumin level was $3.06 \mathrm{~g} / \mathrm{dl}$ (SD $0.69 \mathrm{~g} / \mathrm{dl}$ ). Diminished serum albumin levels were associated with lower CD4 cell counts and weight loss greater than $10 \%$ in relation to habitual weight ( $\mathrm{p}=0.00$ and 0.01 , respectively). BMI, AC, TSF, and time since diagnosis were not significantly associated with serum albumin level.

Statistically significant differences in the CD4 cell count were found in relation to weight loss, serum albumin level, and BMI. The CD4 cell count was not significantly associated with AC, TSF or time since diagnosis (Table 3).

In the overall sample, $84 \%$ were classified as anemic $(86 \%$ of women and $74.28 \%$ of men), with no statistically significant sex

TABLE 2 - Biochemical parameters according to BMI in patients with HIV receiving HAART and hospitalized at the Oswaldo Cruz University Hospital in Recife in Brazil, 2011.

\begin{tabular}{|c|c|c|c|c|c|}
\hline & \multicolumn{2}{|c|}{ Malnourished $(\mathrm{N}=26)$} & \multicolumn{2}{|c|}{ Eutrophic $(\mathrm{N}=24)$} & $\mathrm{p}$-value \\
\hline Leukocytes $\left(\right.$ cells $/ \mathrm{mm}^{3}$ ) & 5.296 & 2.999 & 5.674 & 3.408 & 0.68 \\
\hline Lymphocytes (cells $/ \mathrm{mm}^{3}$ ) & 926.38 & 737.45 & 1313.12 & 794.30 & 0.08 \\
\hline Hemoglobin (g/dl) & 9.57 & 1.81 & 11.11 & 2.46 & 0.01 \\
\hline Albumin (g/dl) & 2.81 & 0.71 & 3.353 & 0.56 & $<0.01$ \\
\hline
\end{tabular}

BMI: body mass index; HIV: human immunodeficiency virus; HAART: highly active antiretroviral therapy. Student's t-test. M: mean; SD: standard deviation.

TABLE 3 - Association among CD4 cell count, albumin level and nutritional measures in patients with HIV receiving HAART and hospitalized at the Oswaldo Cruz University Hospital in Recife, Brazil, in 2011.

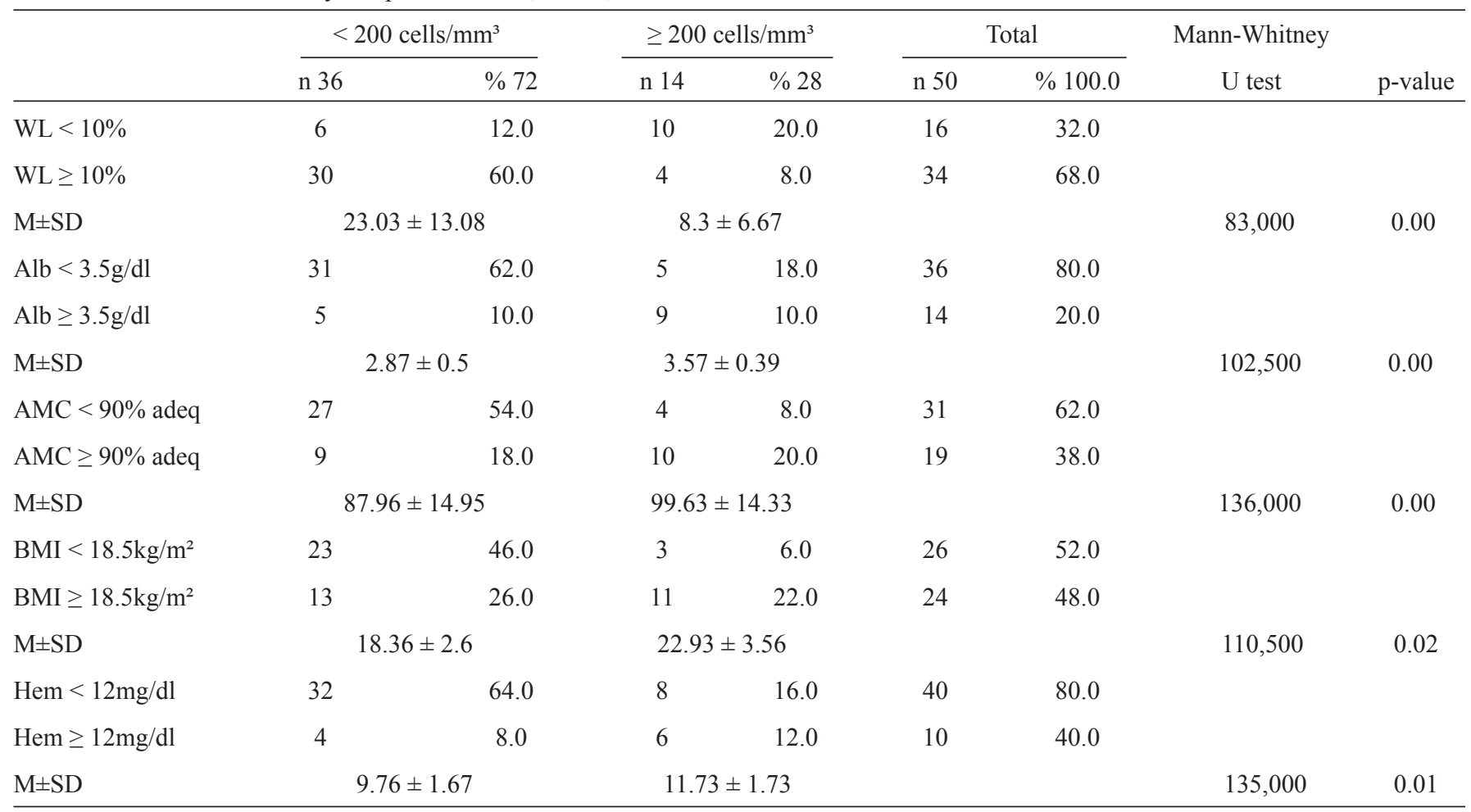

CD4: cluster of differentiation 4; HIV: human immunodeficiency virus; HAART: highly active antiretroviral therapy. Mann-Whitney U test; WL: weight loss; M: mean; SD: standard deviation; Alb: albumin; AMC: arm muscle circumference; BMI: body mass index; Hem: hemoglobin. 
TABLE 4 - Associations among the degree of anemia, BMI, weight loss, albumin level, CD4 cell count and leukocyte count in patients with HIV receiving HAART hospitalized at the Oswaldo Cruz University Hospital in Recife, Brazil, in 2011.

\begin{tabular}{|c|c|c|c|c|c|c|c|c|c|}
\hline & \multicolumn{2}{|c|}{ Severe } & \multicolumn{2}{|c|}{ Moderate } & \multicolumn{2}{|c|}{ Mild/normal } & \multicolumn{2}{|c|}{ Total } & p-value \\
\hline & 9 & 18.0 & 31 & 62.0 & 10 & 20.0 & 50 & 100.0 & \\
\hline CD4 $<200$ cells $/ \mathrm{mm}^{3}$ & 9 & 18.0 & 22 & 44.0 & 4 & 8.0 & 35 & 70.0 & 0.01 \\
\hline $\mathrm{CD} 4 \geq 200$ cells $/ \mathrm{mm}^{3}$ & 0 & 0.0 & 9 & 18.0 & 6 & 12.0 & 15 & 30.0 & \\
\hline $\mathrm{Alb} \geq 3.5 \mathrm{~g} / \mathrm{dl}$ & 0 & 0.0 & 8 & 16.0 & 6 & 12.0 & 14 & 28.0 & 0.01 \\
\hline $\mathrm{BMI}<18.5 \mathrm{~kg} / \mathrm{m}^{2}$ & 6 & 12.0 & 19 & 38.0 & 1 & 2.0 & 26 & 52.0 & \\
\hline $\mathrm{BMI} \geq 18.5 \mathrm{~kg} / \mathrm{m}^{2}$ & 3 & 6.0 & 12 & 24.0 & 9 & 18.0 & 24 & 48.0 & 0.01 \\
\hline $\mathrm{WL}<10 \%$ & 0 & 0.0 & 7 & 14.0 & 8 & 16.0 & 15 & 30.0 & \\
\hline Leuko $>10,000,000$ & 0 & 0.0 & 2 & 4.0 & 3 & 6.0 & 5 & 10.0 & 0.04 \\
\hline
\end{tabular}

BMI: body mass index CD4: cluster of differentiation 4; HIV: human immunodeficiency virus; HAART: highly active antiretroviral therapy; Alb: albumin; WL: weight loss; Leuko: leukocytes. Pearson's chi-squared test and Fisher's exact test.

difference. Regarding the degree of severity, $62 \%$ had moderate anemia and $18 \%$ had severe anemia with no statistically significant sex difference. The degree of anemia was associated with CD4 cell count, albumin level, BMI, weight loss and leukopenia (Table 4).

\section{DISCUSSION}

The Joint United Nations Program on HIV/AIDS (UNAIDS) reports the feminization of HIV, and in sub-Saharan Africa, six in 10 adults living with HIV are currently woman ${ }^{18}$. However, this characteristic was not supported by the findings of the present study, which may be explained by the advanced degree of infection in the patients analyzed, as women are generally more concerned with their health and consequently more likely to adhere to HAART. Moreover, with the introduction of erectile dysfunction medications and the aging of the population worldwide, there has been an increase in the incidence of AIDS among elderly individuals. However, the present sample was composed mainly of young, sexually active, promiscuous individuals.

The findings revealed a malnourished sample with important clinical and biochemical alterations. Despite the introduction of highly active antiretroviral therapy, these characteristics have also been reported by other studies ${ }^{2,3,19}$. The mean BMI in the present investigation differed from that reported by Silva et al. ${ }^{20}$ in 2010 , who found a mean BMI of $24.4 \mathrm{~kg} / \mathrm{m}^{2}\left(\mathrm{SD} 4.3 \mathrm{~kg} / \mathrm{m}^{2}\right)$ in patients receiving HAART in the City of Sao Paulo (Brazil), and that reported by Kroll et al. ${ }^{21}$, who found that the prevalence of excess weight (overweight or obesity) was higher than the prevalence of malnutrition among HIV/AIDS patients ${ }^{21}$. This difference may be explained by the patient profile, as the subjects in the studies cited were in outpatient follow-up, whereas those in the present study were hospitalized and therefore in worse clinical condition.

Based on the BMI, $52 \%$ of the patients were diagnosed with malnutrition. However, the AMC, AC and TSF measures proved to be even more sensitive $(60,82$ and $82 \%$, respectively). Ribeiro $^{22}$ reported similar results, as $41 \%$ of the population analyzed had a BMI $<18.5 \mathrm{~kg} / \mathrm{m}^{2}$. In a study conducted in the City of Porto Alegre (State of Rio Grande do Sul, Brazil) in 2009 , the prevalence of malnutrition among patients using of HAART was only $6.4 \%$ among men and $12.7 \%$ among women ${ }^{23}$. It should be noted that while the population in the study cited used antiretroviral therapy, one of the inclusion criteria was being asymptomatic, which differed from the inclusion criteria of the present study. A study involving hospitalized patients with HIV found results similar to those in the present study regarding malnutrition based on $\mathrm{AC}$ and $\mathrm{AMC}$ measurements, with percentages of 81 and $84 \%$, respectively, but only $5 \%$ based on the TSF, demonstrating that the population analyzed exhibited lean mass depletion but not fat mass depletion ${ }^{24}$. In contrast, the present sample exhibited both lean mass and fat mass depletion.

Oliveira ${ }^{24}$ previously reported a mean serum albumin level of $3.18 \mathrm{~g} / \mathrm{dl}(\mathrm{SD} 0.91 \mathrm{~g} / \mathrm{dl}$ ), which is similar to the value reported herein. Indeed, only $35 \%$ of the sample in the present investigation had serum albumin levels within the range of normality. As a negative acute-phase protein, albumin is a difficult malnutrition indicator to evaluate. 
In 1995, Luder et al. ${ }^{25}$ found that values for anthropometric parameters and CD4 lymphocyte counts were notably lower in patients who had experienced weight loss. The present study confirms this finding, as statistically significant differences were found in some of the anthropometric measures evaluated, in the CD4 cell count and in the serum albumin level between patients with a weight loss $\geq 10 \%$ of their habitual weight and those with a weight loss less than $10 \%$ of their habitual weight. Moreover, associations were found among low albumin levels, belownormal BMI and CD4 cell count $<200$ cells $/ \mathrm{mm}^{3}$ in patients infected with HIV, which is in agreement with findings reported in previous studies ${ }^{6,7}$. These associations are explained by the association of a low CD4 cell count with more advanced stages of infection, implying a higher frequency of opportunistic infections, which affect nutritional status by increasing metabolism and diminishing food intake because of factors such as fever, oral and esophageal lesions, anorexia and diarrhea. A reduced BMI and hypoalbuminemia reflect a reduction in nutritional status characterized by a protein-energy malnutrition.

The prevalence of anemia in patients with AIDS is estimated to be between 63 and $95 \%{ }^{26}$. Thus, the rate of $84 \%$ in the present study is in agreement with findings reported in the literature. This high rate of anemia has multiple causes, such as bone marrow dysfunction caused by the virus, formation of anti-erythrocyte and anti-leukocyte antibodies and certain medications. The reduction in hemoglobin concentration is also caused by the shortage of micronutrients related to hematopoiesis, which is characteristic of severe nutritional deficiencies ${ }^{26}$. Patients with AIDS and the acute phase response are nutritionally compromised and have anemia that does not seem to depend on the recent intake of iron. ${ }^{27}$ Correction of nutritional deficiencies includes the correction of iron deficiency and vitamin B12 and B9 deficiencies that lead to anemia ${ }^{28}$.

Despite the advances achieved with HAART, studies have demonstrated a high incidence of anemia in patients submitted to this form of therapy that seems to be associated with the hematologic toxicity of antiretroviral agents, which can inhibit the formation of progenitor blood cells ${ }^{29}$. Berhane et al. ${ }^{30}$ reported that the use of HAART for six months is sufficient for the development of anemia, which may become aggravated depending on the duration of the use of the drugs. Moyle et al. ${ }^{31}$ reported that patients receiving HAART for 48 weeks may develop anemia and associated this finding with the possible suppression of bone marrow activity induced by the treatment. Other risk factors for anemia in patients with HIV are CD4 cell count $<200$ cells $/ \mathrm{mm}^{3}$, female sex, advanced age, low BMI, African descent and a history of fever and oral candidiasis ${ }^{32}$. In the present sample, anemia severity was associated with a low CD4 cell count, albumin level less than $3.5 \mathrm{~g} / \mathrm{dl}$, BMI less than $18.5 \mathrm{~kg} / \mathrm{m}^{2}$, weight loss higher than $10 \%$ of the habitual weight and leukopenia. These results are associated with the worsening of side effects because of food insecurity that leads to the deterioration of patients' nutritional condition and decreases adherence to the treatment, leading to further progression of the disease, increased resistance to antiretroviral therapy and increased costs of medical care for these patients ${ }^{33}$.
The limitations of this study are related to the lack of consideration of the time of diagnosis or patient adherence to antiretroviral therapy. At the time of data collection, all patients were receiving HAART while hospitalized. Furthermore, because this was a cross-sectional study, we are limited to describing the occurrence of clinical and nutritional characteristics of patients living with HIV/AIDS who were treated at the Hospital Oswaldo Cruz.

In the present study, the population with HIV exhibited worrisome characteristics from a clinical and nutritional standpoint. The high prevalence of malnutrition defined based on all anthropometric measures was associated with anemia, low albumin levels and low CD4 cell counts. These findings underscore the importance of the nutritional evaluation and follow up of hospitalized patients with HIV receiving HAART, as nutritional status is related to other parameters, which, when considered together, affect the condition and quality of life of such individuals.

\section{CONFLICT OF INTEREST}

The authors declare that there is no conflict of interest.

\section{REFERENCES}

1. Wanke CA, Silva M, Knox TA, Forrester J, Speigelman D, Gorbach SL. Weight loss and wasting remain common complication in individuals infected with human immunodeficency vírus in the era of highly active antiretroviral therapy. Clin Infect Dis 2000; 31:803-805.

2. Burgin J, Nichols S, Dalrymple N. The nutritional status of clinical attendees living with HIV/AIDS in St. Vicente and Grenadines. West Indian Med J 2008; 57:438-443.

3. Ludy MJ, Hendricks K, Houser R, Chetchotisad P, Anunnatsiri S. Body composition in adults infected with human immunodeficiency vírus in Khon Kaen, Thailand. Am J Trop Med Hyg 2005; 73:815-819.

4. Salomon J, Truchis P, Melchior JC. Nutrition and HIV infection. Br J Nutr 2002; 87 (suppl I): 111-119.

5. Rezende ELLF, Vasconcelos AMN, Pereira MG. Causes of death among people living with HIV/AIDS in Brazil. Braz J Infect Dis 2010; 14:558-563.

6. Sundaram M, Srinivas CN, Shankar EM, Balakrishnan P, Solomon S, Kumarasamy N. Cofactors for low serum albumin levels among HIVinfected individuals in southern Indian. J Int Assoc Physicians AIDS Care 2009; 8:161-164.

7. Metha SH, Astenborski J, Sterling TR, Thomas DL, Vlahov D. Serum albumin as a prognostic indicator for HIV disease progression. AIDS Res Hum Retroviruses 2006; 22:14-21.

8. Danós JC, Scerpella E, Espinoza L. Anemia severa em pacientes adultos hospitalizados VIH soropositivos em el Jackson Memorial Hospital de la ciudad de Miami. Acta Med Per 2007; 24:15-17.

9. Jan S, RamezaniA, Sabzvari D, Moradmand-Badie B, SeyedAlinaghi S, Jabbari $\mathrm{H}$, et al. A cross-sectional study of anemia in human immunodeficiency virus-infected patients in Iran. Arch Iranian Med 2009; 12:145-150.

10. Levine AM, Berhane K, Masri-Lavine L, Sanchez M, Young M, Augenbraun $\mathrm{M}$, et al. Prevalence and correlates of anemia in a large cohort of HIVinfected women: Women's Interagency HIV Study. J Acquir Immune Defic Syndr 2001; 26:28-35.

11. Creagh T, Mildvan D. Program and abstracts of the $40^{\text {th }}$ Annual Meeting of the Infectious Diseases Society of America (Chicago). Alexandria, VA: 
Infectious Diseaes Society of America; 2002. Greater prevalence of anemia in women and African Americans with HIV/AIDS in the HAART era: a study of 10,000 patients [abstract 475]. The Anemia Prevalence Study Group; p. 127.

12. Centers for Disease Control and Prevention (CDC). Revised Classification System for HIV Infection and Expanded Surveillance Case Definition for AIDS Among Adolescents and Adults [homepage da internet]. Morbidity and Mortality Weekly Report. 1993. Acesso: Dezembro/2011. Disponível em: http://www.cdc.gov/mmwr/preview/mmwrhtml/00018871.htm.

13. Lohman TG, Roche AF, Martorell R. Anthropometric standardization reference manual. Ilinois, USA: Human Kinetics Books; 1988.

14. Chumlea WC, Roche AF, Steinbaugh ML. Estimating sature from knee height for persons 60 to 90 years of age. J Am Geriatric Soc 1985; 33:116-120.

15. Lee RD, Nieman DC. Nutritional assessment of hospitalized patients. In: Lee RD, Nieman DC, editors. Nutritional Assessment. St. Louis: Mosby; 1995. p. 289-332.

16. Frisancho AR. Anthropometric Standards of the assessment of growth and nutritional status. The University of Michigan: Ann Arbor; 1990.

17. Blackburn GL, Thornton PA. Nutritional assessment of hospitalized patients. Med Clin North Am 1979; 63:103-115.

18. Joint United Nations Program on HIV/AIDS (UNAIDS). Together we will end AIDS. 2012. Available at: http://www.unaids.org/en/resources/ campaigns/togetherwewillendaids/unaidsreport/.

19. van der Sande M, van der Loeff MFS, Aveika AA, Sabally S, Togun T, Sargenije R. Body mass index at time of HIV diagnosis, a Strong and independente predictor of survival. J. Acquir Immune Defic Syndr 2004; $7: 1288-1294$

20. Silva EFR, Lewi S, Vedovato GM, Garcia VRS, Tenore SB, Bassichetto KC. Estado nutricional, clínico e padrão alimentar de pessoas vivendo com HIV/Aids em assistência ambulatorial no município de São Paulo. Rev Bras Epidemiol 2010; 677-688.

21. Kroll AF, Sprinz E, Leal SC, Labrêa MG, Setúbal S. Prevalence of obesity and cardiovascular risk in patients with HIV/AIDS in Porto Alegre, Brazil. Arq Bras Endocrinol Metab 2012; 56:137-141.

22. Ribeiro CSA. Prevalência de alterações nutricionais e fatores de risco para desnutrição em pacientes hospitalizados por HIV/AIDS. [Masters Dissertations]. [Salvador]: Escola de Nutrição da Universidade Federal da Bahia; 2010.
23. Rocha PB, Schuch I. Perfil alimentar e nutricional dos pacientes HIV positivo atendidos em um serviço público de saúde de Porto Alegre/RS. Nutrire: Rev Soc Bras Alim Nutr SP; 2009; 34:1-15.

24. Oliveira MRM, Kondo K, Moraes HAB. HIV-Aids e suporte nutricional: Efeito da suplementação alimentar sobre o estado nutricional de homens. Invenio, nov, Ano 8. n. 015. Universidad del centro educativo latinoamericano 2005; 143-154.

25. Luder E, Godffrey ERD, Godbold J, Simpson MD. Assessment of nutritional clinical and immunologic status of HIV-infected, inner-city patients with multiple risk factors. J Am Dietetic Association 1995; 95:655-660

26. Daminelli N, Tritinger A, Spada C. Alterações hematológicas em pacientes infectados pelo vírus da imunodeficiência humana submetidos à terapia antirretroviral com e sem inibidor de protease. Rev Bras Hematol Hemoter 2010; 32:3-4.

27. Monteiro JP, Cunha DF, Cunha SFC, Santos VM, Silva-Vergara LM, Correia $\mathrm{D}$, et al. Iron status, malnutrition and acute phase response in HIV-positive patients. Rev Soc Bras Med Trop 2000; 33:175-180.

28. Argemi X, Dara S, You S, Mattei JF, Courpotin C, Simon B, et al. Impact of malnutrition and social determinants on survival of HIV-infected adults starting antiretroviral therapy in resource-limited settings. AIDS 2012; 26:1161-1166

29. Curkendall SM, Richardson JT, Emons MF, Fisher AE, Everhard F. Incidence of anaemia among HIV-infected patients treated with highly active antiretroviral therapy. HIV Med 2007; 8: 483-490.

30. Berhane K, Karim R, Cohen MH, Masri-Lavine L, Young M, Anastos K, et al. Impact of active antiretroviral therapy on anemia and relationship between anemia and survival in HIV infected women. J Acquir Immune Defic Syndr 2004; 37:1245-1252.

31. Moyle G, Sawyer W, Law M, Amin J, Hill A. Changes in hematologic parameters and efficacy os thymidine analogue-based, highly active antiretroviral therapy: A meta-analysis of six prospective, randomized, comparative studies. Clin Ther 2004; 26:92-97.

32. Volberding PA, Levine AM, Dieterich D, Mildvan D, Mitsuyasu R, Saag M. Anemia in HIV infection: clinical impact and evidence-based management strategies. Clin Infect Dis 2004; 38:1454-1463.

33. Charão APS, Batista MHRS, Ferreira LB. Food insecurity and HIV/ AIDS. Rev Soc Bras Med Trop 2012; 45:751-753. 